\title{
On the Advantages of Constructing Interactive Cooperative Teaching Mode in the Inorganic Chemical Experimental Teaching in Higher Normal Education
}

\author{
Fengchun Wang \\ School of Chemistry, Tonghua Normal University, Jilin Province \\ hunter2011@foxmail.com
}

\begin{abstract}
Keywords: Higher normal university; Inorganic chemistry; Experimental teaching; Interactive cooperative teaching.
\end{abstract}

\begin{abstract}
Inorganic Chemistry Experimental course is an important basic compulsory course for students with chemistry major, which can lay solid foundation in the whole process of learning chemical professional knowledge. By starting from the inorganic chemical experimental courses in university, this paper analyzes the construction of interactive cooperative teaching mode and introduces the acceleration effect of interactive teaching mode on the inorganic chemical courses in higher normal university.

In the higher normal education, inorganic chemical experimental course is one important component of chemistry major as well as the compulsory course for students of chemistry major and an important course to consolidate the basic chemical theoretical knowledge of students. The accuracy of inorganic chemistry experimental course requires that the students should have certain experimental operation ability and grasp some creation skills; besides, it should pay attention to the cultivation of creativity of students at the same time of improve students' operational ability. Therefore, inorganic chemical experimental course can greatly improve the comprehensive quality of the teachers and students of chemistry major in higher normal university and it is also the essential requirement for chemistry major in the teaching process to improve the inorganic chemical experimental mode in higher normal university.
\end{abstract}

\section{Reform on the Inorganic Chemical Mode}

The status quo of inorganic chemical course in higher normal education. (1) Monotonous teaching mode. In the inorganic chemical course of most higher normal universities in China, the monotonous teaching mode is one remarkable question which can affect the teaching effect. Most teachers follow the enclosed teaching mode and are not willing to give up the traditional teaching mode; therefore, they only pay attention to the teaching of knowledge on books but ignores the cultivation of students' practicability; thus leading to the monotonous of teaching pattern and invisibly depressing the development of comprehensive quality in the major.

(2). More teaching contents and less time. Since inorganic chemistry is a discipline with many theories and high practicality, it is relatively hard to teach compared with other professional subjects. Besides, with the development of time, the knowledge referred by inorganic chemistry is more and more widely and with more and more information, which requires the teachers to increase the teaching time. However, quite the contrary, teachers often take some parts for the whole and only teach the important and difficult points and ignore some knowledge; therefore, students are hard to learn systematic inorganic chemical knowledge in the process. In other words, the learned inorganic chemical knowledge is scattered, which would increase the difficulty for learning and decrease the learning interests. And the study is only for passing the exams.

(3). Lack of teaching experiments. Most teachers still adopts monotonous teaching methods and teaches only by their mouth but ignores the basic effect of experiments in the teaching of inorganic chemical courses. For inorganic chemical major, experiment is the only way to understand and grasp the knowledge on the books. For some micro knowledge, the understanding from the books is like a building in the desert for it lacks the solid foundation. In the same way, if the students lack of 
teaching experiments, it is hard to imagine the micro world of inorganic chemistry with their brain. Therefore, it would increase the cognition and increase the difficulty for learning inorganic chemistry.

Essentiality of Interactive cooperative teaching mode. Interactive cooperative teaching mode refers to the interaction between students and teachers and the communication of learning experience under the guidance of teachers so as to construct a good learning environment and learning mechanism and form a virtuous circle so as to stimulate the students' learning enthusiasm and cultivate students' creativity and innovation ability. The interactive cooperative teaching mode gets rid of the monotonous teaching environment in the past, increase the experience communication and emotion communication between students as well as the communication between students so as to realize the interrelation and harmony between teaching and learning. This interactive teaching mode can greatly promote the relation between students and teachers and form good teaching environment and teaching mechanism for the interaction between students and teachers.

\section{Methods for Constructing Interactive Cooperative Teaching}

Construction of equal relation between teachers and students. New interaction relation between students and teachers is the requirement for developing education career in the new curriculum reform. Equal and harmonious students and teachers' relation is the prerequisite and guarantee for the success of teaching process; meanwhile, good interaction between teachers and students can promote the development of teaching, improve teaching quality and teaching effect. Without equal and harmonious interaction between teachers and students, it is hard to conduct normal teaching activity no matter what excellent ability and professional quality the teachers have. The students should actively get close students, care students and respect the individuality of students so as to undertake the role of "teacher and friend"; instead, they should not have conflicts with students just because they are teachers. For example, teachers should regularly communicate with students like friends, know the difficulty on study and life in recent times. Teachers can also establish a long-term and stable sense of trust by tutoring the students' inorganic chemical experiments report, find out their weakness and discuss with all the students; and encourage the students who can make excellent experiment report by saying "well done!", "try harder next time" so as to increase the students' confidence and establish good competitive consciousness.

Establishing livable experiment class and increase interaction between teachers and students. Classroom is a micro society, in which teachers and students are only two roles in the classroom. The interaction between teachers and students is an interaction. The interaction between teachers and students can activate the micro society; the lack of it would make the micro society an inactive and dull environment. During teaching process, the teachers can organize the students for exploratory learning by the way that teachers propose questions and students collect data and design the experiment process automatically and obtain the answers to the questions. By thinking with questions, students and teachers can form interactive learning and discussion and establish livable experiment courses. The concrete procedures are the followings:

(1) Teachers are well-prepared for the teaching process. Teachers should be familiar with the difficulty and important points in the teaching process and communicate with students before the class to understand the structure of knowledge points and timely adjust the structure of teaching plan based on the actual situation of students so that students can better accept the new knowledge and increase teaching effect. In the teaching process, teachers adopt heuristic teaching methods to activate their learning willingness and transfer passive learning into active learning. For example, in the experiment of making and purification of potassium nitrate whose formula is $\mathrm{NaNO} 3+\mathrm{KCL}=\mathrm{NaCl}+\mathrm{KNO}$. The experiment theory is to control the temperature by human beings so as to abstract the potassium nitrate by the difference of solubility of different substance so as to interactively communicate and discuss with students; then the students can grasp the experiment theory. The interaction can change the autonomous classroom activity and fully practice the thinking ability of students. 
(2) By classroom tips, teachers can make heuristic teaching for students to make interactive teaching mode between students and teachers. Before comprehensive experiments, teachers can give students some tips and guidance by setting up situations. For example, in the above mentioned making and purification of potassium nitrate, teachers can propose the following questions:(1) why the water dissolving of potassium nitrate should base on the proportion of $2: 1$ ? (2) what is the purpose of heating potassium nitrate? (3) why the filtration of potassium nitrate solution is necessary? If not, what would happen? (4) why the crystal after cooling the potassium nitrate solution is raw product? What else is there in the crystal?

(3). By group experiment competition to activate the experiment enthusiasm of students. The study of basic experiment is the basis for inorganic chemical teaching. The whole class would be divided into five groups and it would set up a common test theme. The students can determine the experiment plan by communication and autonomous experiments. In the classroom, the teachers inspect the students so as to timely rectify and affirm the experiments of students. Meanwhile by applying the students' willingness to win and competitive mentality, it can form good competition in the group competition and adjust the enthusiasm of students to do experiments, which can increase students' operational ability and team spirit.

\section{Analysis on the advantages of interactive cooperative teaching}

Cultivate students' creativity by optimizing the teaching contents. In the traditional inorganic chemical experiments courses, basic testifying experiments occupy a large proportion. For example, in the book Inorganic Chemistry Experiments published by Beijing Normal University, above half of the contents are basic testifying experiments. Although basic testifying experiment is an important part of inorganic chemistry, it can increase the students' observation and grasp for basis knowledge in the book; it is not beneficial for the development of time and cannot cultivate students' innovation ability. In recent years, affected by new curriculum reform, some universities actively change inorganic chemical textbook and reduce the proportion of basic testifying experiments, increase many comprehensive experiments and adding some new technical elements, such as nanotechnology, composition of AIPO4, which can greatly increase students' creativity; meanwhile, university teachers change the traditional teaching mode and adopts interactive teaching modes between students and teachers and promote the communication between teachers and students, which can increase the students' learning interest; by increasing interesting experiments, such as 'chemical ice bag' 'DIY hand warmer", it can greatly promote the diversified development of inorganic chemistry.

Improve teaching effect by diversified teaching method. With the development of inorganic chemistry, various new science and technology appear one after another, which provide more choices for the teaching methods. By making inorganic chemistry experiments teaching by multimedia and teachers demonstrate the experiments, which can make the inorganic chemistry class more vivid and concrete, and make the students have a more comprehensive and vivid knowledge for the experiments and greatly improve the class effect. For example, in the experiments of "preparation of solution and titration operation practice", teachers should firstly teach the usage of experimental equipment and play the teaching video in the class; then teachers should demonstrate the experiment process again and teach each link one by one so that students can have a comprehensive grasp of the experiments details. Finally, teachers can invite two group students to test in the platform and analyze; then the teachers tell the experiments report in front of all the students. Teachers should fully play the multimedia teaching methods in inorganic teaching process and adopts the on-site methods to fully represent the advantages of interactive cooperative teaching modes and enhance communication and interaction between teachers and students, which can increase emotion between teachers and students and increases the teaching effect.

Emphasize the practicability ability by improving checking system. Because of the strong practicability in inorganic chemistry course, the checking of inorganic chemistry is not suitable for adopting the paper examination of disciplines in other majors. As for the checking results, teachers 
should evaluate according to results in ordinary time and operation checking and operational checking; usually performance occupies $60 \%$ and operational testing occupies $40 \%$. The high proportion of ordinary checking result can better guarantee the learning enthusiasm. As for the checking of ordinary experiment results, the students' performance and the experiment results would occupy $20 \%$. Finally, based on the scores of experiments, then the teachers would evaluate the final ordinary results. This evaluating system can truly reflect the learning situation of each student and avoid the situation that students do not work hard in ordinary time and only works hard when the final exam comes. Meanwhile, the teachers can look over and observe the experiment results to guide individually; students can grasp the experiments skills easily and well practice the students' operational practicablity.

Realize "greening" chemical experiments. With the global economic development, the environment pollution is inevitable, which is more severe in many developing countries. In environmental problems, chemical industry is the main source. In order to solve the problem, people need to improve the pollution of chemical industry to realize the greenization of chemistry. In order to respond the calling of environment protection, the experiment courses in inorganic courses in higher normal university, there would be many chemical wastes in the teaching process of inorganic chemical experiments. If the university does not properly handle it, it would cause irreversible pollution for the environment. In the teaching process, teachers and students should build up the the consciousness of "green chemistry". In the teaching process, it should reduce the waste rate of chemical products. Valuing every chemical reagent and classify the waste of chemical experiments to make it return to the chemical waste recycle stations by proper channels. Universities should deal with it from source based on the principle of "prevention is better than governance" to guarantee the greening of experiments teaching in inorganic chemistry. It should abandon heavy metal such as $\mathrm{Hg}$, benzene etc and use chemical products which has little pollution and is easy to recycle; and it should enhance the management for chemical experiment waste and reduce the random emission of experiment waste.

\section{Conclusion}

Affected by new curriculum reform, inorganic chemical experiment courses in higher normal university would adopt some bold reform in the renewing of educational contents and construction of interactive cooperative teaching mode so that it can consolidate students basic knowledge, improve their practibility and creativity. The construction of interactive cooperative teaching mode stimulates the reform of inorganic chemical course and makes innovation for more aspects of experimental course. Adopting diversified teaching method would promote the chemical experiment course,improve students' comprehensive quality, enhance the equality and harmony relation between students and teachers, which would promote the educational career more effective and sustainable.

\section{Reference}

[1]Yang Tianlin, Yang Wenyuan \& Ni Gang. Reform of experimental teaching---for greening chemistry---taking the inorganic chemistry experiment teaching as example. Experimental Technology and Management,2012,29(4)

[2] Zhou Yinmei.Application of interactive teaching mode in inorganic chemical experiment teaching. Examination Weekly,2013,(38)

[3]Liu Li. Some thoughts about the experimental teaching of inorganic chemical experiment teaching in university. Twelfth National Chemistry forum essays[C].2013.

[4] Zhang Zhong. About the trying and exploratory of improving inorganic chemistry experiment courses quality in higher normal universities.Educational Teaching Forum,2014,(8) 